\section{Prospects for European co-operation in science}

\author{
G. Szigeti, Observer on behalf of EPS, and member of EPS Executive \\ Committee, reports on the Unesco meeting of experts on science policy \\ selected by Governments of the European Member States in Budapest \\ from 4-7 July 1972.
}

In his speech of welcome, the Hungarian Minister Dr. G. Csanadi emphasized the role of co-operation in scientific research, and expressed his hope that the efforts for the collective security of the European peoples would be successful because the existence of mankind depended upon it. It appeared to him that the one task of the meeting was to elaborate definite proposals for Governments to support the further development of science. Dr. Csanadi stated that the Hungarian Government had accepted a long-term scientific programme for the period up to 1985 .

It had been drawn up after careful preparation and aimed to secure the peaceful development of science by modest means. He expressed his regret that, at the present time, not every European country was able to attend. On behalf of the Hungarian Government, Dr. Csanadi wished that meeting success with its work.

Professor I. Malecki, Representative of the Director-General of Unesco, welcomed the experts to the meeting. $\mathrm{He}$ expressed the view that science serves as a connecting link between North and South, East and West, and that it is destined to reconcile political conflicts. Professor Malecki was convinced that the Budapest meeting would be able to provide the appropriate climate.

Professor F. Csaki (Hungary) was elected President of the meeting, with Professor P. Flubacher (Switzerland) and Professor A. Straszak (Poland) as Vice-Presidents. In his opening Presidential address, Professor Csaki stated that the reprsentatives of the German. Democratic Republic (GDR) were not able to participate because only experts from Member States were allowed to be present at Unesco meetings, and the GDR was not yet a Member. Professor Csaki said that their forum was not competent to settle the question of the Membership of the GDR.

The agenda contained many of the questions raised at the EPS Council Meeting in Oslo in March (Europhysics News 33 (April 1972)) and I expressed this opinion in my contribution to the meeting. Below is my summary of the results of the meeting which closely follows the official communique. The meeting was a progressive step to improve the co-ordination and efficiency of the European scientific work initiated by Unesco.

\section{PREAMBLE}

The committee of experts started by discussing the group of countries represented at the meeting.

Some expressed the view that the meeting could not be considered a full European meeting because representatives from the GDR had not been invited. This was the more regrettable in that the GDR is a country with a large and advanced science sector ; thus, it was to be hoped that, at least, the GDR would be invited to future meetings to the mutual benefit of all the European countries.

Others argued that this problem could in no way be a proper one for the present meeting ; that the question belonged to those discussed in other meetings, the nature of which was very different from the present one, at which the experts were scientists and science policy administrators; and that it would be improper for them to engage in such purely political issues, not to mention decisionmaking in this area.

In general, the meeting expressed the opinion that the scope and intensity of regional co-operation in various fields of science and technology will depend to a considerable degree on the continuing development of a favourable political climate in Europe and of an atmosphere of confidence and mutual understanding among European countries.

In this connection, however, some experts were of the opinion that the proposed Conference of Heads of Governments of European States on Security and Co-operation would play a significant role as a step towards establishing a system of collective security and creating such a favourable atmosphere. In the opinion of these experts, Unesco's contribution to the preparation of the above Conference could be : (a) to formulate basic principles of European scientific co-operation;

(b) to indicate concrete priority areas and fields of science for co-operation ;

(c) to elaborate forms and methods of regional and sub-regional cooperation suited to specific problem areas and fields of science.

Other experts, however, felt that the question of a role for Unesco and other international organizations in the preparation of the proposed Conference was not a matter on which this meeting could usefully pronounce.

The meeting, being a result of the 1970 ministerial meeting, also discussed its relationship to future ministerial meetings and the frequency of these. It seemed important to strike a balance between, on the one hand, the need for ministerial meetings to take place at intervals sufficiently short to enable adequate guidance to be given to the direction of science policy and, on the other hand, the importance of allowing sufficient time for follow-up action to be taken and meetings to be adequately prepared.

One of the issues alluded to a number of times was the science of science policy. The complexity of modern society, the need for better planning and the difficulties involved in this function, raised more and more frequently the demand for scientific analyses and firm data on which the planning could be based.

How science should be organized to meet this challenge was an extremely complex question. However, a more developed science of science policy may give a partial answer. Though relatively new, this field is now approaching the point of 'takeoff'. Its function is partly to enable rational discussions in science policy as such, and partly to enable science policy to find its proper place within the framework of overall socio-economic policy. The importance of this need not be underlined.

In the present state of the art, one useful way of assisting its development would be the convening of small expert meetings to evaluate the ways and means by which science policy studies could be promoted. It would be the responsibility of such meetings to make concrete proposals relating to the individual Governments, and to consider possible international co-operation in this field. No desire for an international research institute was expressed; but it might well be that certain national institutes could be made to function as international centres. 
Another point discussed in some detail was the possibility of facilitating the mobility of scientists. There was general agreement that the exchange of scientists was one of the most fruitful ways of furthering European co-operation. It was also felt that, generally speaking, the financing of this form of co-operation should be considered a national obligation. In this connection, reference was made to the role of research councils and academies. The mobility of the scientists should be a function of the needs of the research workers themselves ; it should also take account of national priorities. It was pointed out that, if centres likely to attract foreign scholars were to play their proper role in this respect, they must be provided with the necessary facilities.

Many experts stressed the role of Unesco as an important centre of knowledge about the science policy actually carried out by member countries. The Unesco 'data-bank' gave a much-needed possibility for exchanges of information on an overall European- and even on a world-scale.

This was only one of the many facilities for the promotion of European co-operation, which could be provided by Unesco, by other organizations like the United Nations Economic Commission for Europe, and by other regional organizations. It was important that this network be fully utilized. Unesco may help in this respect by disseminating information on available programmes, by initiating pilot studies on the availability of certain unique scientific instruments, and by co-operating with interested national bodies and international organizations (both inter-governmental and non-governmental) in the comparative analysis of organized forms of co-operative action.

The experts also touched upon future expert meetings. The view was expressed - and supported - that the efficiency of such meetings should be secured by a careful selection of coherent and narrowly defined problems, the discussion papers being prepared by selected experts.

In the course of the meeting a series of possible areas and modalities for strengthening European scientific co-operation were suggested. There was no attempt to draw up an exhaustive list, nor to rank the suggestions according to whether intensive co-operation was already taking place. The list reproduced below is, consequently, only tentative, and is to be submitted by Unesco to the governments for further consideration.
Areas

Organized multilateral co-operation in basic and fundamental sciences

1 Science of science

2 Theoretical and applied mathematics and cybernetics

3 Nuclear physics

4 Solid-state physics

5 Informatics and computer sciences

6 Macromolecular physics and chemistry

7 Molecular biology

8 Oceanography

9 Meteorology

10 Seismology

Co-operation in non-market-oriented applied research

1 Social needs of modern society

2 Medical research and health

3 Transport and communication systems

4 Ecology and the protection of the environment

5 Peace, conflict and disarmament research

\section{Co-operation in science and}

technology services

1 Scientific and technical information and documentation

2 Transfer of technology

\section{Modalities}

1 Joint (international) research centre

2 National research centre with regional vocation

3 Common research programme (jointly managed and/or co-ordinated)

4 Scientific meetings (symposia, workshops, etc.)

5 Exchange of scientists

6 Exchange of information (programmes and/or results).

\section{RECOMMENDATIONS}

The Committee of Experts recommended to the European Member States, to Unesco and to other competent international organizations that they pursue vigorously all possibilities for strengthening European co-operation in science.

More particularly the Committee recommended, in the furtherance of the above aim :

To European Member States :

1 that they make full use of the following mechanisms :

(i) international congresses, conferences, symposia, workshops, etc., focusing on narrowly defined topics or on subjects of an interdisciplinary nature ; (ii) professional, national scientific and/or technical associations, and the international scientific unions ;

(iii) bilateral and multi-lateral links between the leading national scientific research bodies (such as the national research councils or the academies of sciences) ;

(iv) direct lines of communication between educational institutions engaged in research work (such as universities, colleges and other institutions of higher education).

2 to develop their international cooperation strategies in science and technology giving due consideration to :

(i) national objectives and the national science policy-making processes ;

(ii) the need for national systems for the dissemination and utilization of the results of such co-operation :

(iii) the choice of the managerial and executive structures most appropriate to the various forms of international co-operation involved ;

(iv) existing multi- and bilateral links at governmental and nongovernmental level;

(v) the role of the national research councils and academies of sciences in promoting the exchange of scientists among European countries, the importance of providing these bodies with adequate funds for the purpose, and the need for expanding the facilities of the research institutes acting as their hosts.

To the European Member

States and to Unesco :

1 to strengthen scientific and technological co-operation in Europe primarily by making fuller use of the existing research facilities and by distributing the work involved in cooperative international programmes among institutions in the various countries of Europe or its subregions as the case may be.

2 to consider ways of initiating a European programme on science policy research.

3 to continue and enhance the support of the centres of excellence based upon national research laboratories and/or universities gradually taking up a regional or international role.

4 to take note with satisfaction of the proposals for concrete co-operation 
in five specific fields of science shortly to be submitted by scientists from Austria, Czechoslovakia, Hungary, Italy, Poland, Romania and Yugoslavia, in liaison with Unesco to the governments of the countries participating in the scheme, and to take note with particular interest of the fact that this scheme aims at defining ad hoc international agreements open to all interested European Member States.

\section{To Unesco :}

1 to help promote within the scientific community of the region, primarily through Unesco's European Bureau for scientific co-operation, the following principles :

(i) that in active scientific work the unofficial, international co-operation between scientists and scientific institutions has been and will continue to be an important form of communication;

(ii) that co-operation in science and movements of scientists should have their roots in the needs of scientific research itself and should also take account of national priorities ;

(iii) that, like science itself, the pattern of co-operation and exchange should continue to be pluralistic ;

(iv) that the academies, research councils and other research supporting organizations have an important role to play in fostering co-operation in European and world science.

2 to take, without prejudice to the above principles, all other measures as may be appropriate, to promote scientific contacts within such priority research fields as may from time to time be selected for European co-operation.

3 to conduct a survey of 'big science' taking into account the facilities which exist in Europe, and to give a view of existing capacity to accommodate foreign research teams or individual scientists.

4 to make a comparative analysis of the respective merits and demerits of the various existing vehicles, mechanisms and modalities of European scientific co-operation.

To the competent

International Organizations :

To support the guidelines set out in this recommendation, and to contribute, whenever appropriate and feasible, to their full implementation.

\section{United Nations Conference on the Human Environment}

After four years of preparation, the United Nations Conference on the Human Environment took place in Stockholm from 5-18 June 1972. Government delegations from more than 100 countries, representatives of international organisations, and several hundred observers met and discussed the problems of man and his environment. The European Physical Society was invited to attend this conference as a NonGovernmental Observer. D.J. Kroon from Eindhoven, the Netherlands, represented the EPS and he gives his opinion on this important meeting.

It is, of course, impossible to give a concise report on a meeting as the Stockholm conference. Several hundred talks, statements and reports were presented on a great variety of problems concerning the human environment. Air and water pollution, seas and oceans, social and economic problems, development strategy, food contamination, international trade, monitoring systems and many other subjects were treated in more, or less, detail. This report has, therefore, to be incomplete and reflects only a few aspects of the conference.

\section{Preparations}

In 1968 the Swedish government proposed that the United Nations should convene an international conference on the human environment 'because air pollution, water pollution, erosion, soil deterioration, unplanned urbanisation, traffic congestion, noise, etc., were rising at an alarming rate'.

The General Assembly of the United Nations accepted the proposal, established a preparatory committee, and appointed the Canadian Maurice F. Strong as Secretary General of the Conference. Consultations took place with more than 100 governments, with international organisations, with United Nations agencies and with many other groups. Several hundred reports were made and these resulted in six studies of 'subject areas' to be discussed during the conference :

1 Planning and management of human settlements for environmental quality.

2 Environmental aspects of natural resources management.

3 Identification and control of pollutants of broad international significance.

4 Educational, informational, social and cultural aspects of environmental issues.

5 Development and environment.

6 International organizational implications of action proposals.

These reports were the background of the 'Action plan for the human environment'. Each subject area report contained a long list of 'Recommendations for action', in which a great number of practical suggestions and measures were set out. Besides this action plan, a 'Declaration on the human environment', in which the principles of international behaviour and responsibilities were laid down, was one of the main topics of the conference.

\section{The Conference}

For the discussion of such a great number of problems of such different nature with so many delegations, two weeks was not enough. The Conference was therefore divided into four parallel sessions. Three committees discussed the reports mentioned above. Here, especially, the recommendations for action were considered and sometimes very carefully reformulated. These recommendations are to be the basis of laws in different countries, and hence precise agreements were necessary.

To give an example: One of the recommendations in subject area 3 was : 'It is recommended that Governments use the best practicable means to minimize the release to the environment of persistent and toxic substances, particulary heavy metals and organochlorine compounds...'. After quite a discussion this was changed to '... toxic or dangerous substances, especially if they are persistent, such as.... Although the result of this type of discussion is very important for future international action, the discussion itself is not very inspiring.

Besides these committee meetings, which were held every morning and afternoon (some even during the week-end) plenary sessions of the conference were convened twice each day. Here, the general policy, problems, backgrounds, measures and basic ideas were outlined as they existed in different countries. Also, international organizations which were involved with the environment in some 